\title{
Efficient Low Driving Force Charge Separation in an Electron Deficient Zn-Porphyrin-Fullerene Donor-Acceptor Conjugate
}

\author{
Maximilian Wolf $₫$, Joana I. T. Costa $\ddagger$, Martin B. Minameyer $§$, Thomas Drewello , \\ Augusto C. Tomé $\ddagger$, and Dirk M. Guldi § \\ $\S$ Department Chemistry and Pharmacy Friedrich-Alexander-University Erlangen-Nuremberg \\ Egerlandstraße 3, 91058, Erlangen, Germany \\ ${ }^{\ddagger}$ QOPNA \& LAQV-REQUIMTE, Department of Chemistry University of Aveiro 3810-193 Aveiro, Portugal.
}

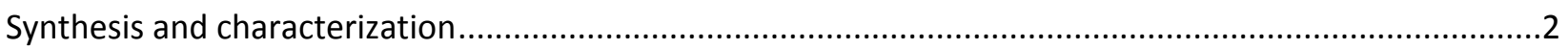

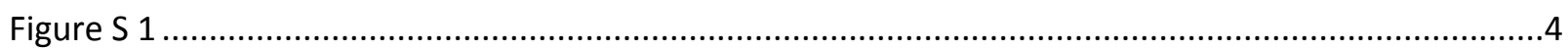

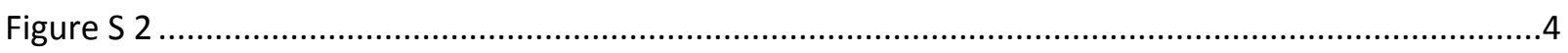

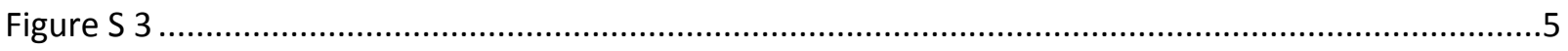

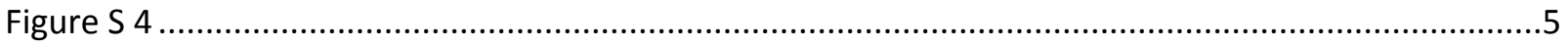

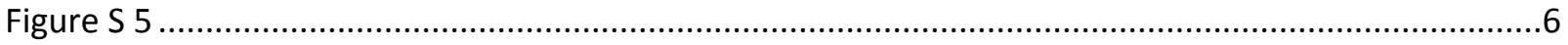

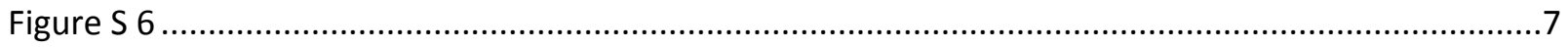

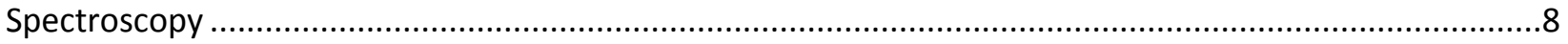

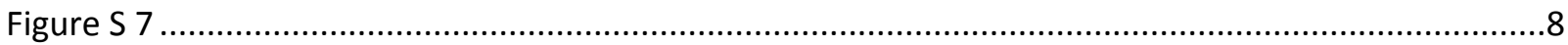

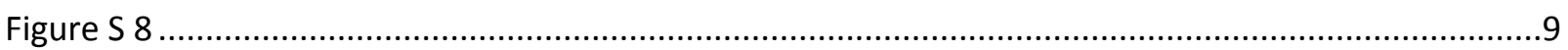

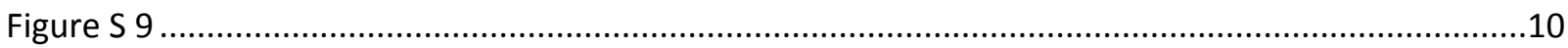

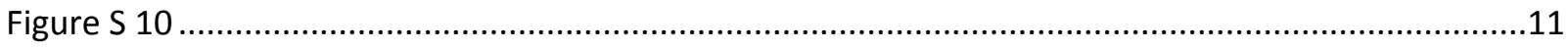

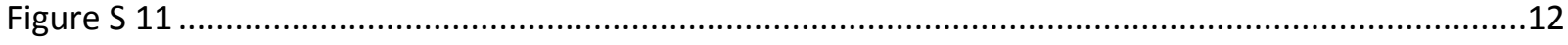

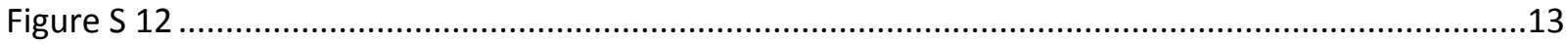

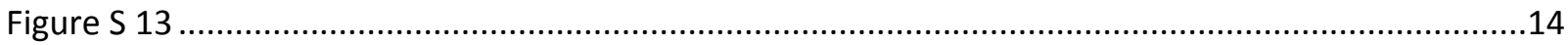

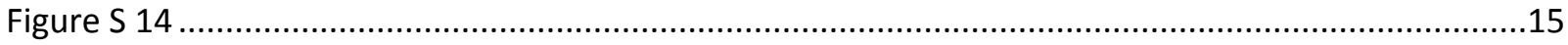

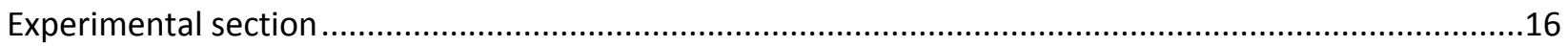




\section{Synthesis and characterization}

The $\mathrm{ZnTF}_{5} \mathrm{PP}-\mathrm{C}_{60}$ conjugate 1 was synthesized by the following synthetic route:
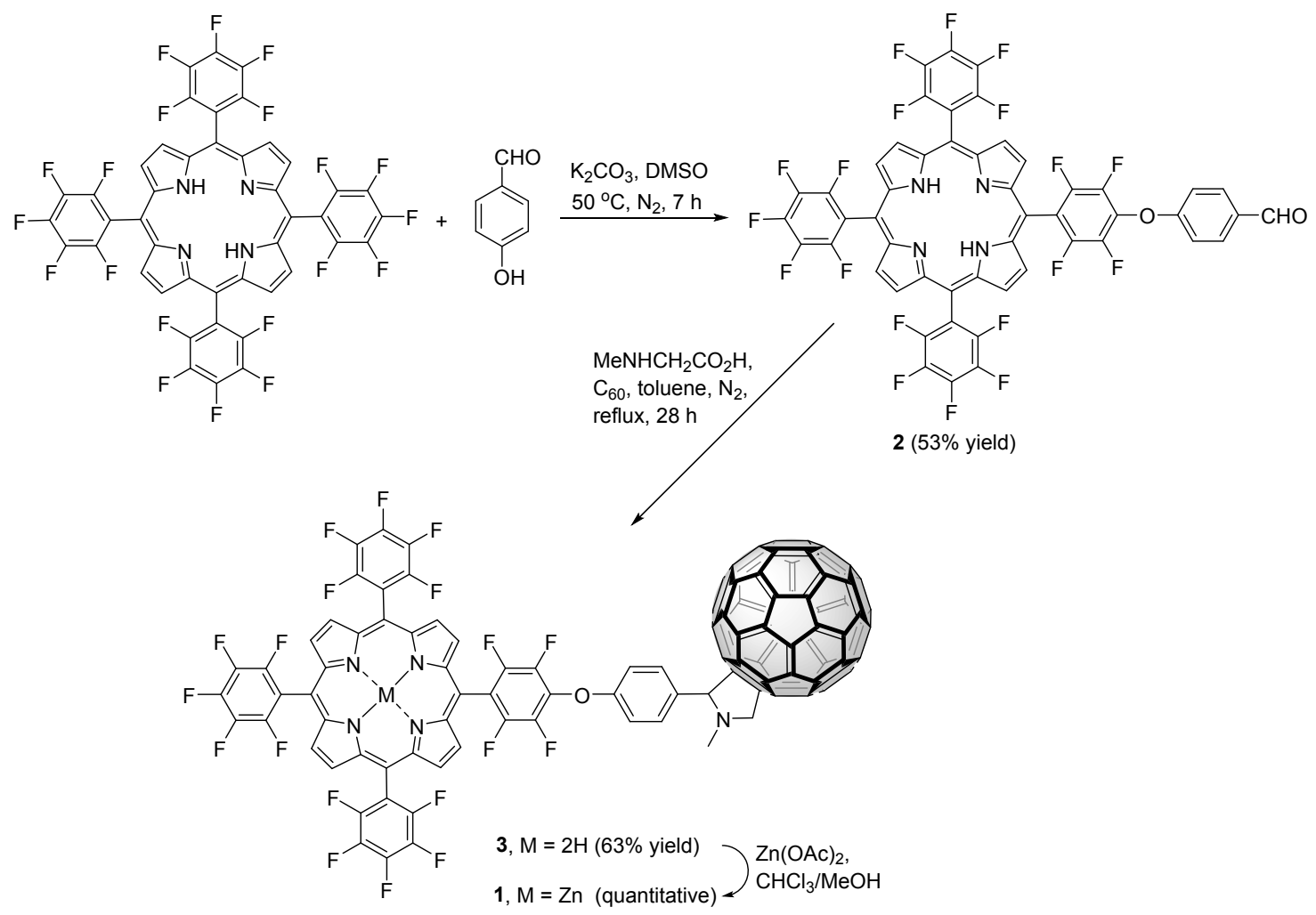

\section{Synthesis of the 4-(porphyrinyloxy)benzaldehyde 2}

To a solution of $\mathrm{TF}_{5} \mathrm{PP}(100.0 \mathrm{mg}, 0.103 \mathrm{mmol}, 1.5$ equiv.) and 4-hydroxybenzaldehyde $(8.4 \mathrm{mg}, 68.4 \mu \mathrm{mol})$ in dry DMSO ( $3 \mathrm{~mL}$ ) was added potassium carbonate $(47.3 \mathrm{mg}, 0.342 \mathrm{mmol}, 5$ equiv.). The reaction mixture was stirred at $50{ }^{\circ} \mathrm{C}$ for $7 \mathrm{~h}$ under a nitrogen atmosphere. After cooling to room temperature, an aqueous solution of citric acid was added to the reaction mixture and the porphyrinic material was precipitated. After filtration, the solid was dissolved in dichloromethane and washed with water. The organic phase was dried over anhydrous sodium sulfate and the solvent was evaporated to dryness on the rotary evaporator. The residue was dissolved in dichloromethane and purified by silica gel column chromatography using dichloromethane/hexane (2:1) as the eluent. The first fraction was the unreacted $\mathrm{TF}_{5} \mathrm{PP}$ ( $45 \mathrm{mg}$ recovered) and then the mono-substituted porphyrin 2 (39 mg, 53\% yield) was collected, which was further crystallized from dichloromethane/hexane. Two minor fractions were also isolated and identified as the 5,15 - and 5,10-di-substituted porphyrins ( $3 \mathrm{mg}$ ( $4 \%$ yield) and $8 \mathrm{mg}$ ( $11 \%$ yield), respectively.

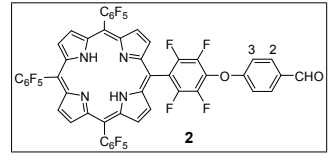

${ }^{1} \mathrm{H}$ NMR $\left(300 \mathrm{MHz}, \mathrm{CDCl}_{3}\right) \delta:-2.90(\mathrm{~s}, 2 \mathrm{H}, \mathrm{NH}), 7.45(\mathrm{~d}, J=8.6 \mathrm{~Hz}, 2 \mathrm{H}, \mathrm{H}-3), 8.09$ (d, J $=8.6 \mathrm{~Hz}, 2 \mathrm{H}, \mathrm{H}-2), 8.93-9.01(\mathrm{~m}, 8 \mathrm{H}, \mathrm{H}-\beta), 10.08(\mathrm{~s}, 1 \mathrm{H}, \mathrm{CHO}) \mathrm{ppm} .{ }^{19} \mathrm{~F}$ NMR $(282$ 
$\mathrm{MHz}, \mathrm{CDCl}_{3}$ ) $\delta:-162.03$ to $-161.84\left(\mathrm{~m}, 6 \mathrm{~F}, \mathrm{C}_{6} \mathrm{~F}_{5}-m-\mathrm{F}\right),-153.88$ (dd, $J=23.4$ and $\left.9.8 \mathrm{~Hz}, 2 \mathrm{~F}, \mathrm{C}_{6} \mathrm{~F}_{4}-\mathrm{m}-\mathrm{F}\right),-151.9$ to $-151.71\left(\mathrm{~m}, 3 \mathrm{~F}, \mathrm{C}_{6} \mathrm{~F}_{5}-p-\mathrm{F}\right),-137.2\left(\mathrm{dd}, J=23.3\right.$ and $\left.7.8 \mathrm{~Hz}, 6 \mathrm{~F}, \mathrm{C}_{6} \mathrm{~F}_{5}-\mathrm{o}-\mathrm{F}\right),-136.92(\mathrm{dd}, J=23.4$ and $9.8 \mathrm{~Hz}$, $\left.2 \mathrm{~F}, \mathrm{C}_{6} \mathrm{~F}_{4}-\mathrm{O}-\mathrm{F}\right)$ ppm. ${ }^{13} \mathrm{C}$ NMR $\left(75 \mathrm{MHz}, \mathrm{CDCl}_{3}\right) \delta: 103.5,116.2,132.3,132.8,161.3,190.5$ (CHO) ppm. UV-vis $\left(\mathrm{CHCl}_{3}\right) \lambda_{\max }(\log \varepsilon): 412$ (5.2), 505 (4.3), 539 (sh), 583 (4.1), 636 (3.9) nm. MS (MALDI) m/z: 1076.1 [M] ${ }^{+\bullet}$. HRMS (ESI) $m / z$ : calculated for $\mathrm{C}_{51} \mathrm{H}_{16} \mathrm{~F}_{19} \mathrm{~N}_{4} \mathrm{O}_{2}[\mathrm{M}+\mathrm{H}]^{+}$1077.0964, obtained 1077.0957.

\section{Synthesis of the porphyrin- $\mathrm{C}_{60}$ conjugate 1}

A mixture of porphyrin 2 (30.0 mg, $27.9 \mu \mathrm{mol}), \mathrm{N}$-methylglycine $\left(14.9 \mathrm{mg}, 0.167 \mathrm{mmol}, 6\right.$ equiv.) and $\mathrm{C}_{60}$ (40.1 mg, $55.7 \mu \mathrm{mol}, 2$ equiv.) in dry toluene $(40 \mathrm{~mL}$ ) was refluxed under nitrogen for $28 \mathrm{~h}$. The reaction mixture was concentrated on the rotary evaporator and purified by silica gel column chromatography using toluene/hexane (1:1) as the eluent. The first fraction was the unreacted $\mathrm{C}_{60}$ (14 $\mathrm{mg}$ recovered); then conjugate 3 was collected and crystallized from toluene/hexane ( $32 \mathrm{mg}, 63 \%$ yield). Metallation with zinc acetate in $\mathrm{CHCl}_{3} / \mathrm{MeOH}$ at $50 \stackrel{\circ}{\circ}$, afforded the conjugate 1 in quantitative yield.

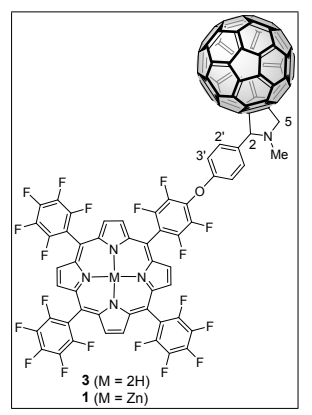

Data for the conjugate 3: ${ }^{1} \mathrm{H}$ NMR $\left(300 \mathrm{MHz}, \mathrm{CDCl}_{3}\right) \delta:-2.93(\mathrm{~s}, 2 \mathrm{H}, \mathrm{NH}), 2.88(\mathrm{~s}, 3 \mathrm{H}$, $\left.\mathrm{CH}_{3}\right), 4.29(\mathrm{~d}, J=9.6 \mathrm{~Hz}, 1 \mathrm{H}, \mathrm{H}-5), 5.00-5.03(\mathrm{~m}, 2 \mathrm{H}, \mathrm{H}-2$ and $\mathrm{H}-5), 7.38(\mathrm{~d}, J=8.5 \mathrm{~Hz}$, $2 \mathrm{H}, \mathrm{H}-3^{\prime}$ ), 7.88-8.01 (br s, 2H, H-2'), $8.92(\mathrm{~s}, 6 \mathrm{H}, \mathrm{H}-\beta), 8.98(\mathrm{~d}, J=4.1 \mathrm{~Hz}, 2 \mathrm{H}, \mathrm{H}-\beta) \mathrm{ppm}$. ${ }^{19} \mathrm{~F}$ NMR $\left(282 \mathrm{MHz}, \mathrm{CDCl}_{3}\right) \delta:-162.03$ to $-161.85\left(\mathrm{~m}, 6 \mathrm{~F}, \mathrm{C}_{6} \mathrm{~F}_{5}-\mathrm{m}-\mathrm{F}\right),-154.1$ (dd, $J=23.1$ and $\left.9.1 \mathrm{~Hz}, 2 \mathrm{~F}, \mathrm{C}_{6} \mathrm{~F}_{4}-m-\mathrm{F}\right),-151.97$ to $-151.78\left(\mathrm{~m}, 3 \mathrm{~F}, \mathrm{C}_{6} \mathrm{~F}_{5}-p-\mathrm{F}\right),-137.66$ (dd, $J=23.1$ and $9.1 \mathrm{~Hz}, 2 \mathrm{~F}, \mathrm{C}_{6} \mathrm{~F}_{4}-\mathrm{O}-\mathrm{F}$ ), -137.1 (dd, $J=23.7$ and $\left.7.8 \mathrm{~Hz}, 6 \mathrm{~F}, \mathrm{C}_{6} \mathrm{~F}_{5}-\mathrm{O}-\mathrm{F}\right) \mathrm{ppm}$. UV-vis (toluene) $\lambda_{\max }$ (log $\varepsilon$ ): 416 (5.5), 508 (4.6), 545 (sh), 586 (4.4), 640 (4.2) nm. 


\section{Characterization of conjugate 1}

NMR

Note: $\mathrm{A}{ }^{13} \mathrm{C}$ NMR spectrum has been recorded, but the multitude of couplings between ${ }^{13} \mathrm{C}$ and ${ }^{19} \mathrm{~F}$ nuclei prohibit meaningful analysis of the spectrum. ${ }^{1} \mathrm{H}$ and ${ }^{19} \mathrm{~F}$ spectra are presented in the following.

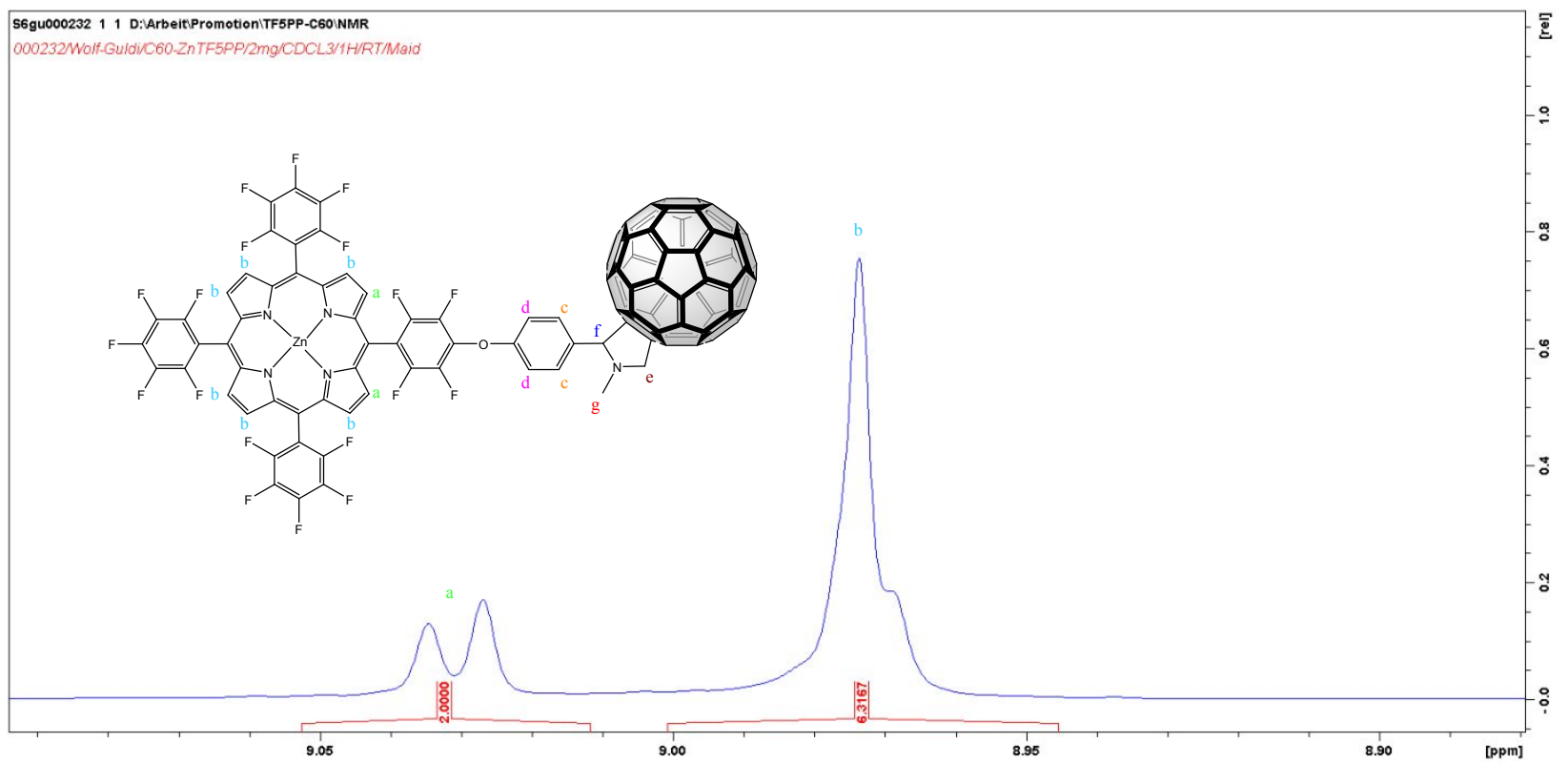

Figure $\mathrm{S}$ 1: $\beta$-pyrrolic region of the ${ }^{1} \mathrm{H}-\mathrm{NMR}$ spectrum recorded in $\mathrm{CDCl}_{3}$

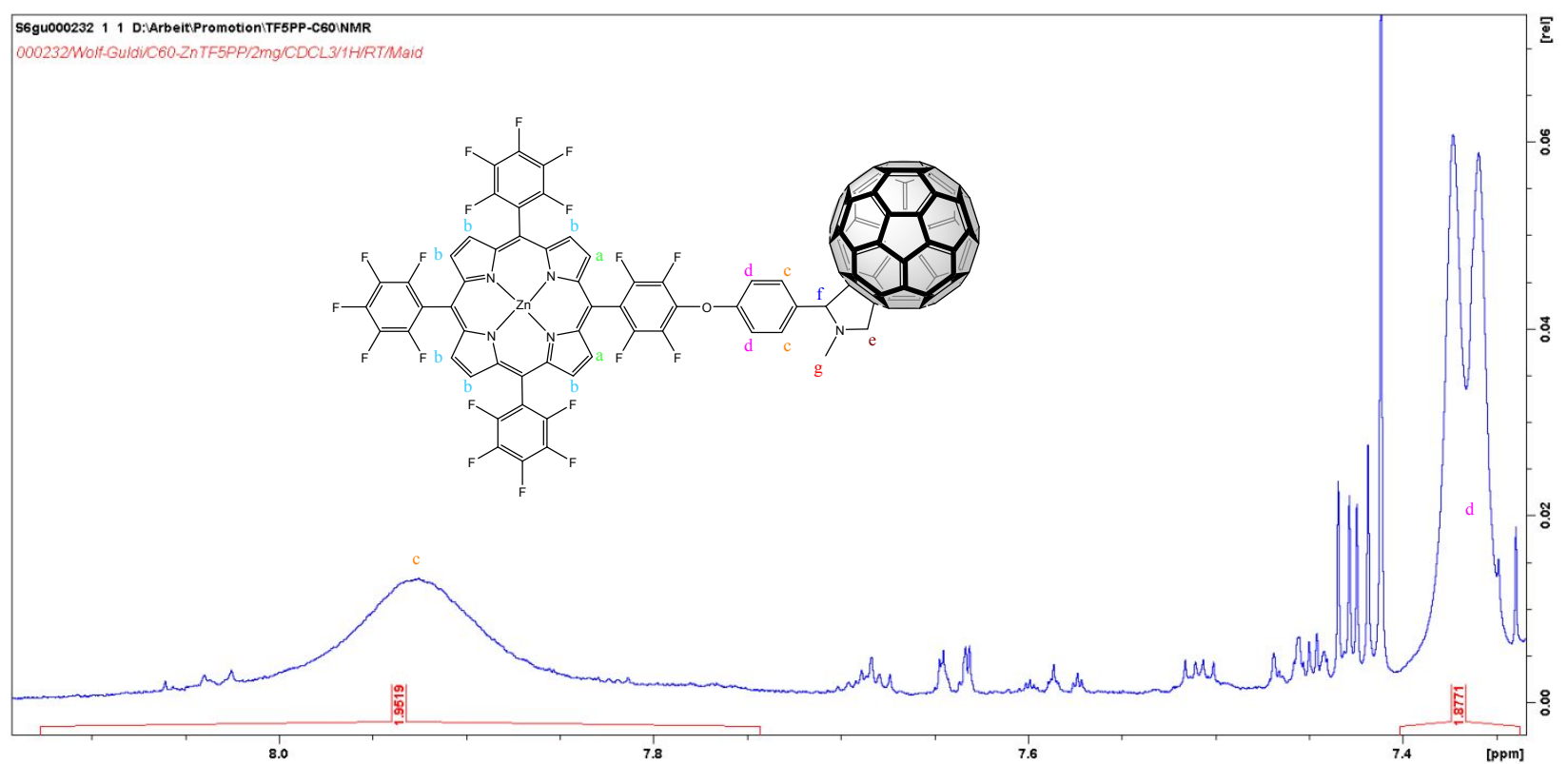

Figure $\mathrm{S}_{2}$ : aromatic region of the ${ }^{1} \mathrm{H}-\mathrm{NMR}$ spectrum recorded in $\mathrm{CDCl}_{3}$.

Note: due to coupling with the diastereotopic, readily flipping proton (f) the signals of the protons (c) coalesce to one broad signal. Due to the high resolution of the instrument, impurities stemming from solvents used in the synthesis are visible in the range of 7.4 to $7.7 \mathrm{ppm}$. 


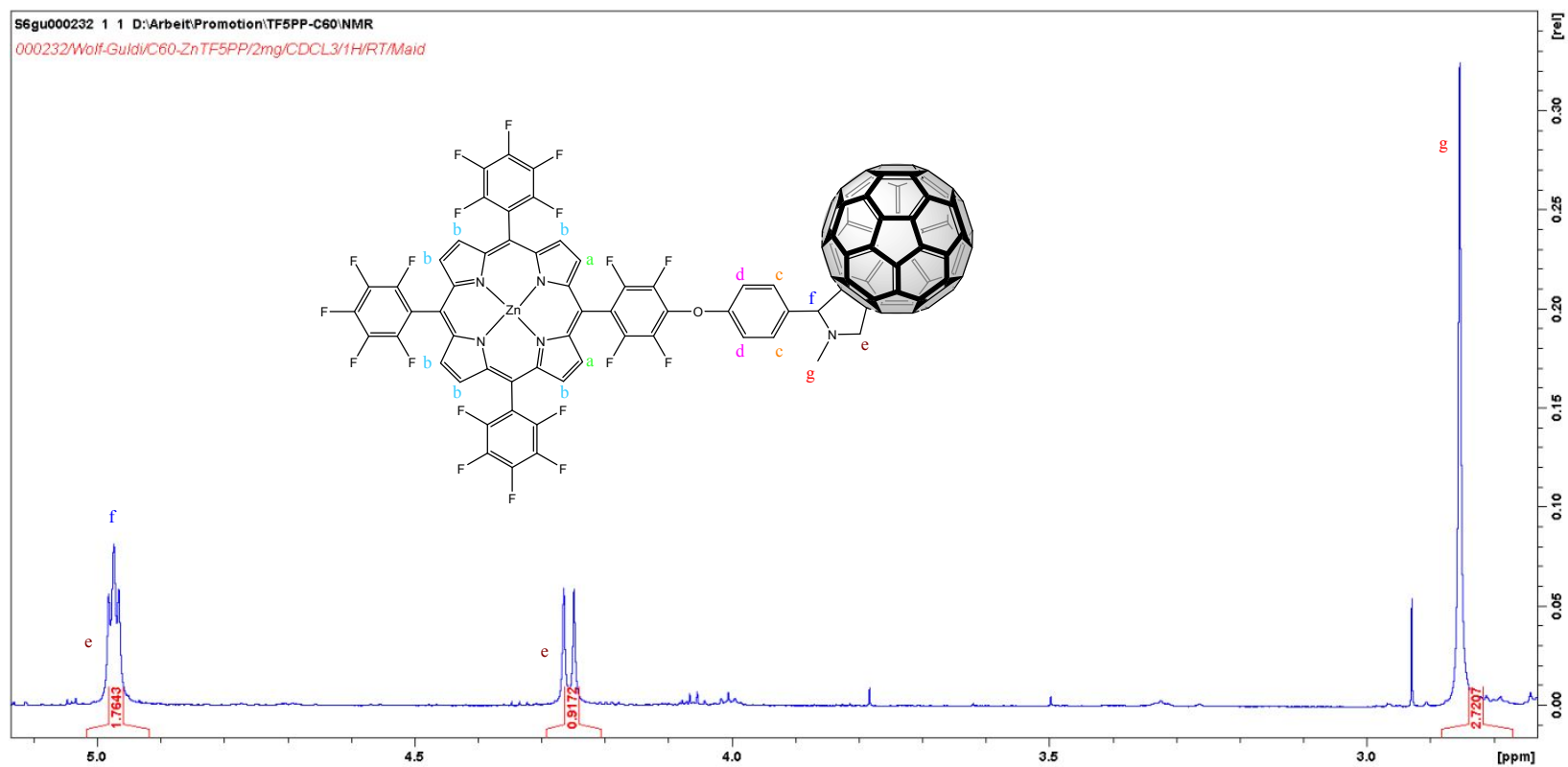

Figure $\mathrm{S}_{3}$ : aliphatic region of the ${ }^{1} \mathrm{H}-\mathrm{NMR}$ spectrum recorded in $\mathrm{CDCl}_{3}$.

Note: the signal near $5 \mathrm{ppm}$ is a pseudo-triplet composed of one part of the doublet of doublets of the protons (e) and the singlet of the proton (f). A measurement at $350 \mathrm{~K}$ leading to independent shifts of the signals in the pseudo-triplet confirmed this assignment.

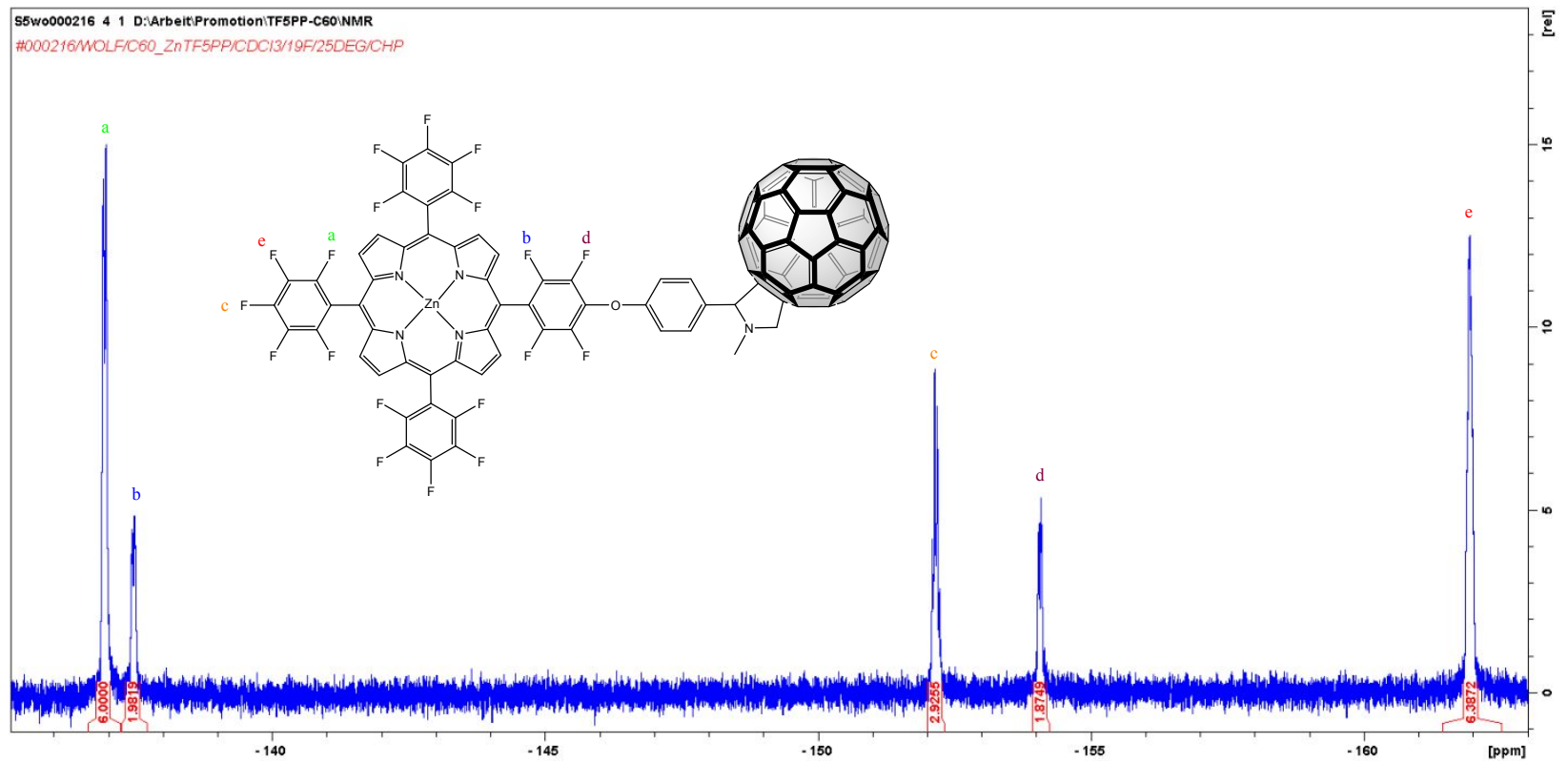

Figure $\mathrm{S}_{4}$ : ${ }^{19} \mathrm{~F}-\mathrm{NMR}$ spectrum recorded in $\mathrm{CDCl}_{3}$. 


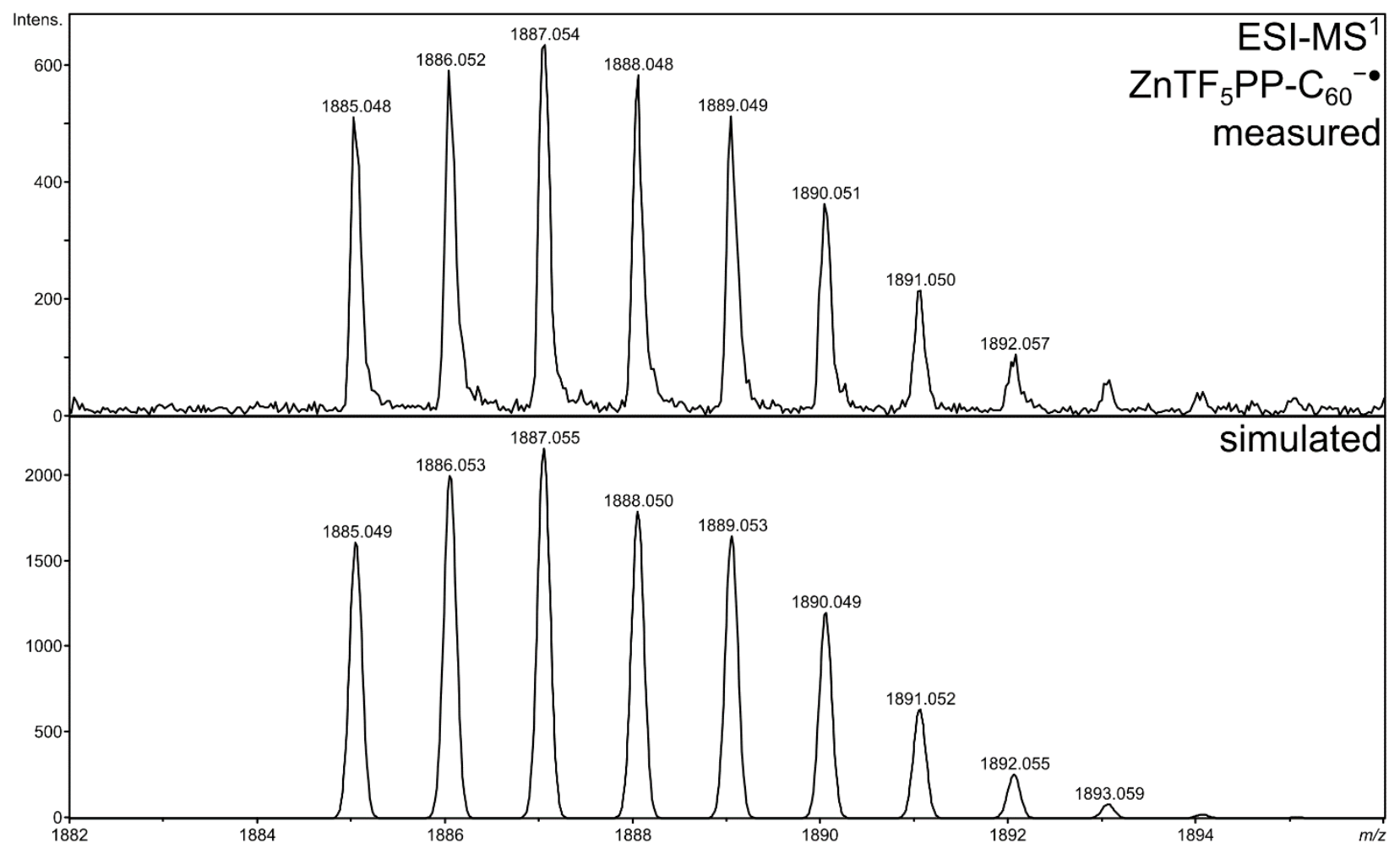

Figure S 5: Top: ESI mass spectrum of $\mathbf{1}$ displaying the measured isotope distribution of the corresponding radical anion. Bottom: simulated isotope pattern of the radical anion of $\mathbf{1 .}$ 


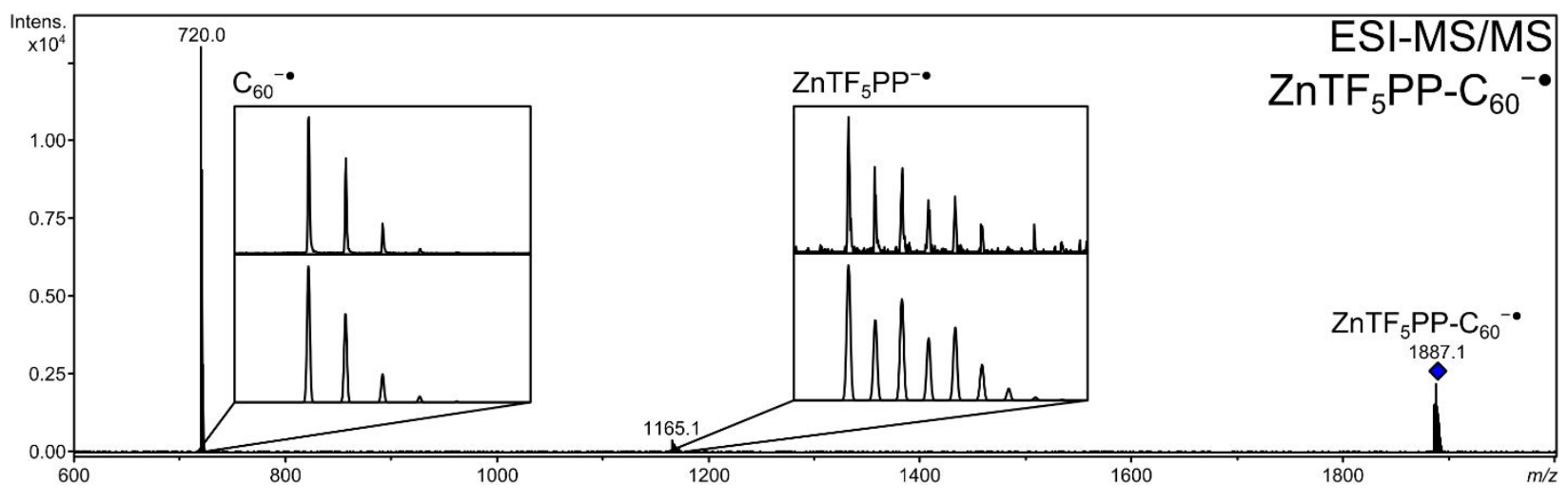

Figure S 6: MS/MS spectrum of $\mathbf{1}^{-\bullet}$ with the blue diamond indicating the mass-selected precursor ion. Insets show the measured isotope pattern of the fragment ions with the respective simulated pattern below. The fragment ions can be assigned to the radical anion of $\mathrm{C}_{60}$ at $\mathrm{m} / \mathrm{z} 720.0$ and the radical anion of $\mathrm{ZnTF}_{5} \mathrm{PP}$ at $\mathrm{m} / \mathrm{z}$ 1165.1. The intensity ratio of the fragment ions clearly indicates that the negative charge is preferably located at the fullerene. 


\section{Spectroscopy}

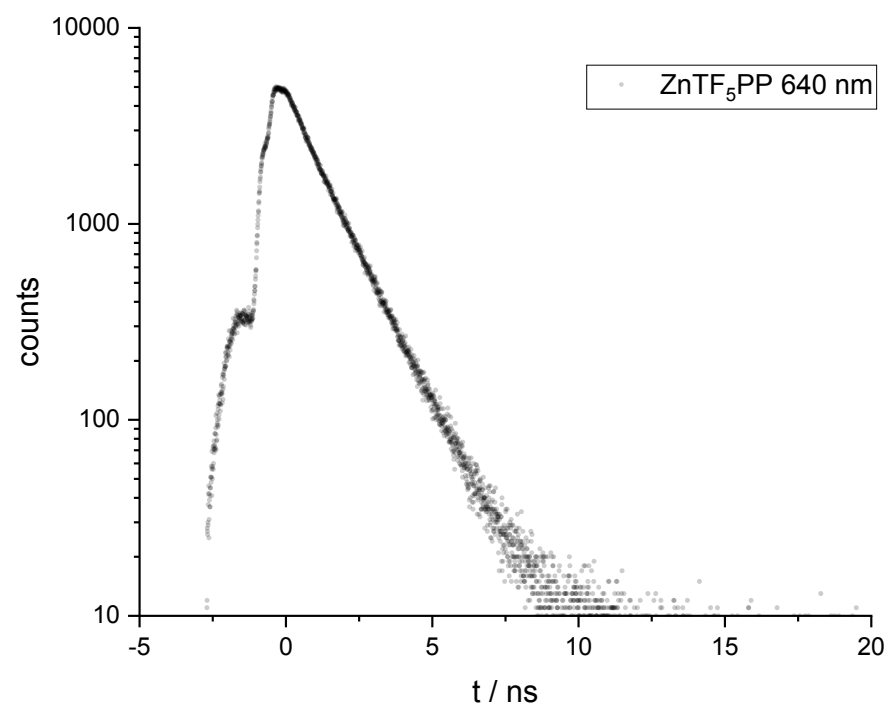

Figure $\mathrm{S}_{7}$ : decay of $\mathrm{ZnTF}_{5} \mathrm{PP}$ main emission peak at $640 \mathrm{~nm}$ in Toluene as obtained by TCSPC. Excitation at $420 \mathrm{~nm}$. 

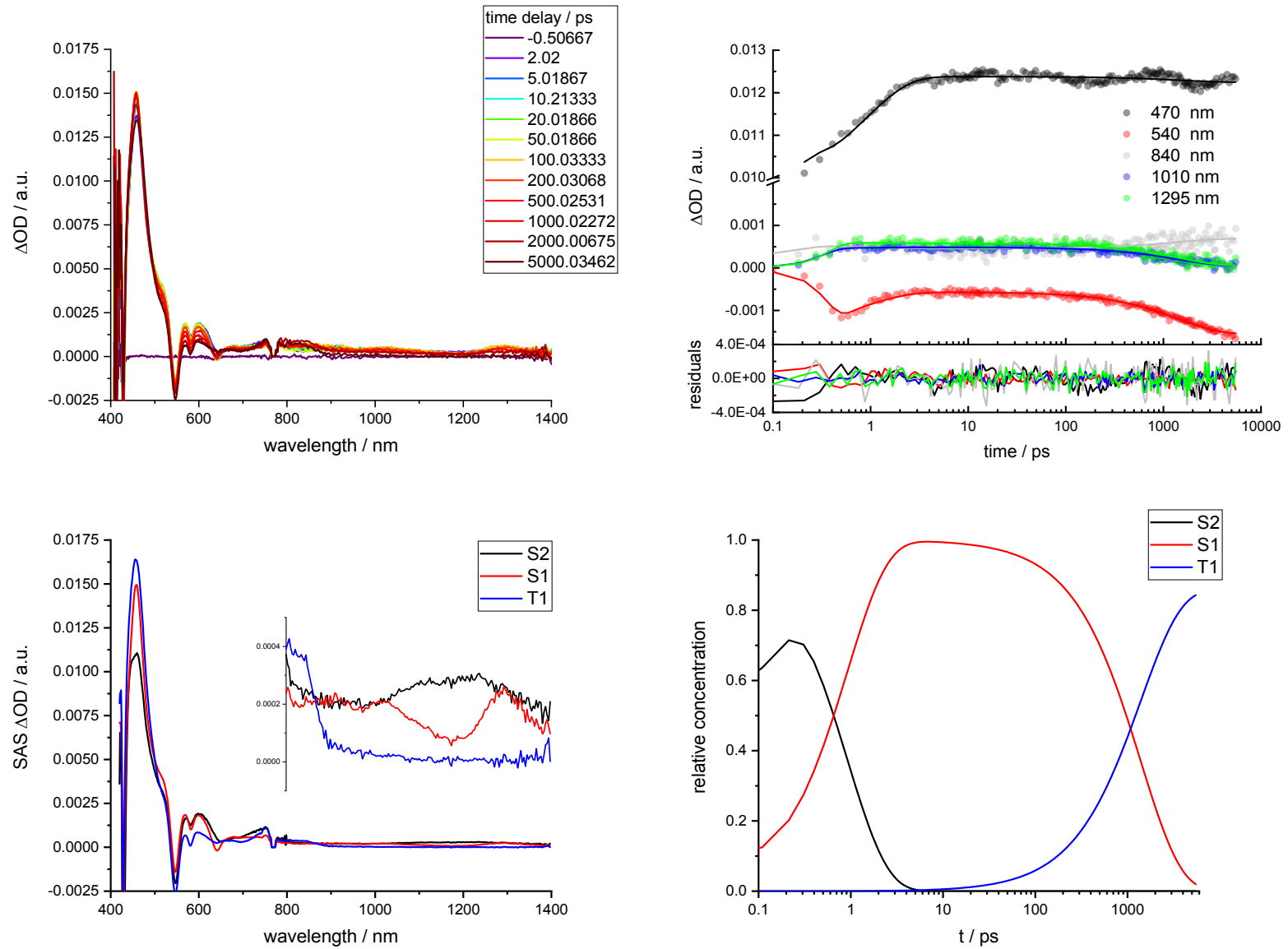

Figure S 8: Transient absorption results of $\mathrm{ZnTF}_{5} \mathrm{PP}$ on the sub-ps to ns time scale in Toluene upon excitation at $430 \mathrm{~nm}$; detector change and probe fundamental at $775 \mathrm{~nm}$. Top left: raw data (vis and NIR) with time delays from -0.5 to $5000 \mathrm{ps}$ after excitation. Top right: time profiles of important features and the corresponding fits / residuals obtained from global target analysis. Bottom left: Species associated spectra (SAS) obtained from global target analysis (vis and NIR). Bottom right: time-concentration profiles of the species obtained from global target analysis. 

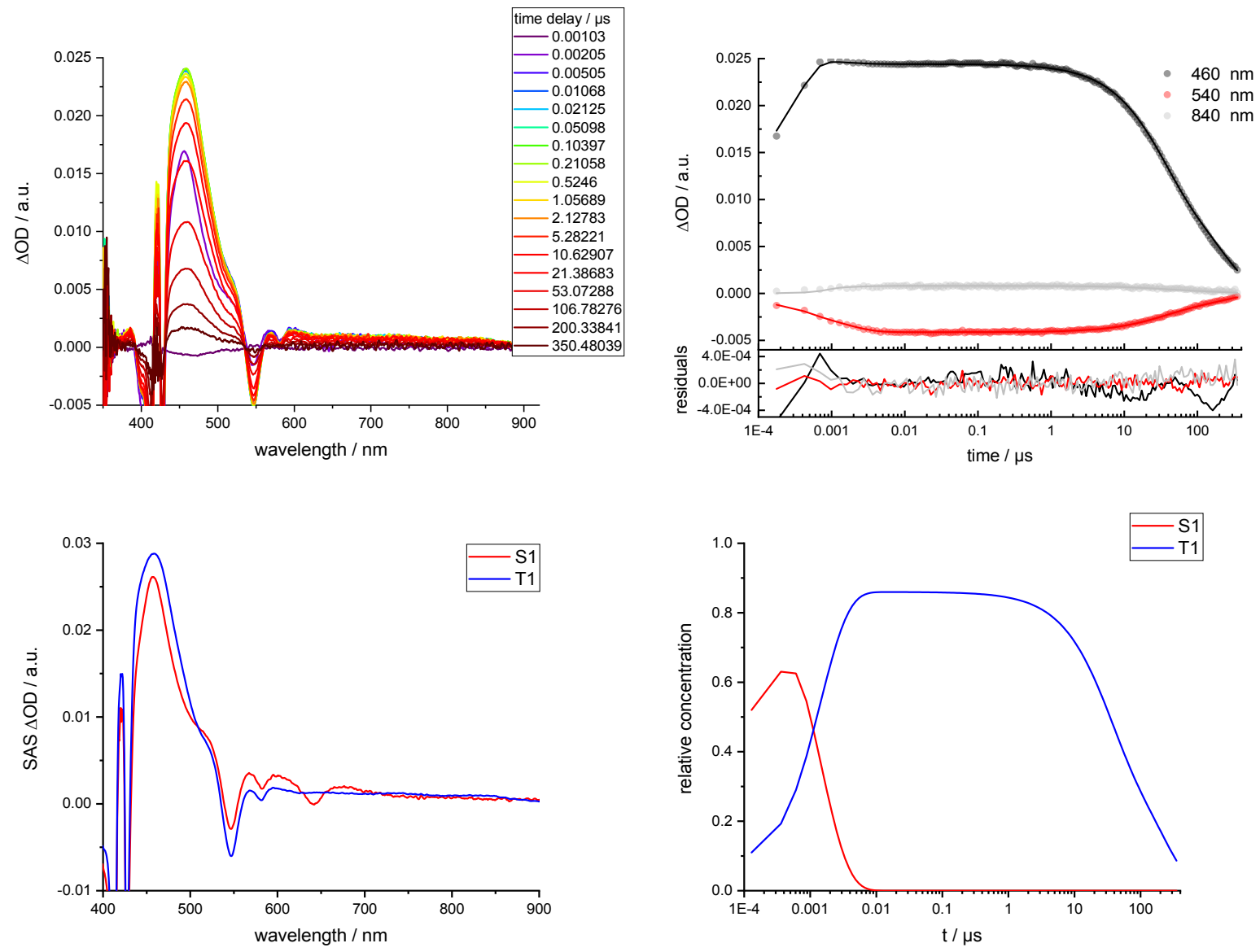

Figure S 9: Transient absorption results of $\mathrm{ZnTF}_{5} \mathrm{PP}$ on the ns to $\mu$ s time scale in Toluene upon excitation at $430 \mathrm{~nm}$. Top left: raw data (vis to NIR) with time delays from o.oo1 to $350 \mu$ s after excitation. Top right: time profiles of important features and the corresponding fits / residuals obtained from global target analysis. Bottom left: Species associated spectra (SAS) obtained from global target analysis (vis to NIR). Bottom right: time-concentration profiles of the species obtained from global target analysis. Note: the S2 state cannot be resolved here due to the time resolution of $\sim$ ins. 


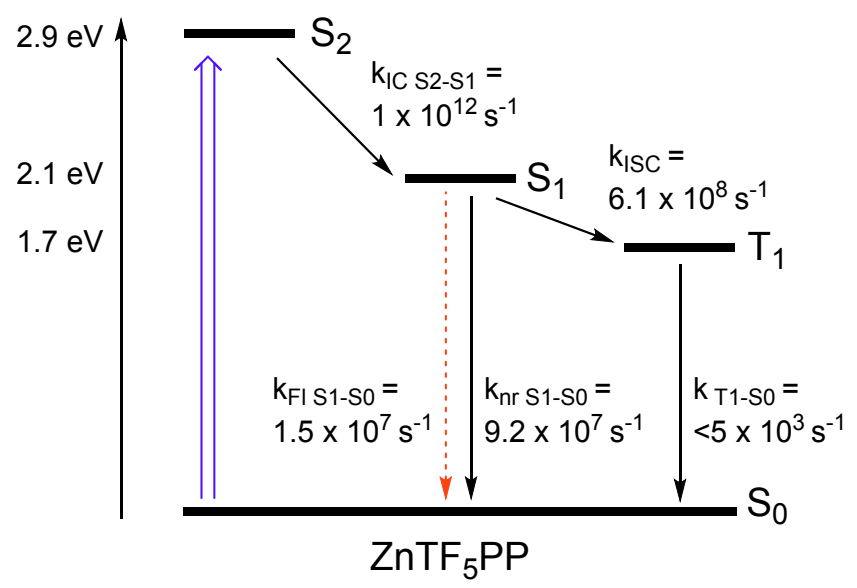

Figure $\mathrm{S}$ 10: energy diagram and reaction rates of the excited state deactivation of $\mathrm{ZnTF}_{5} \mathrm{PP}$, combining results from the sub-ps to ns, on one hand, and ns to $\mu$ s timescale measurements, on the other hand. 


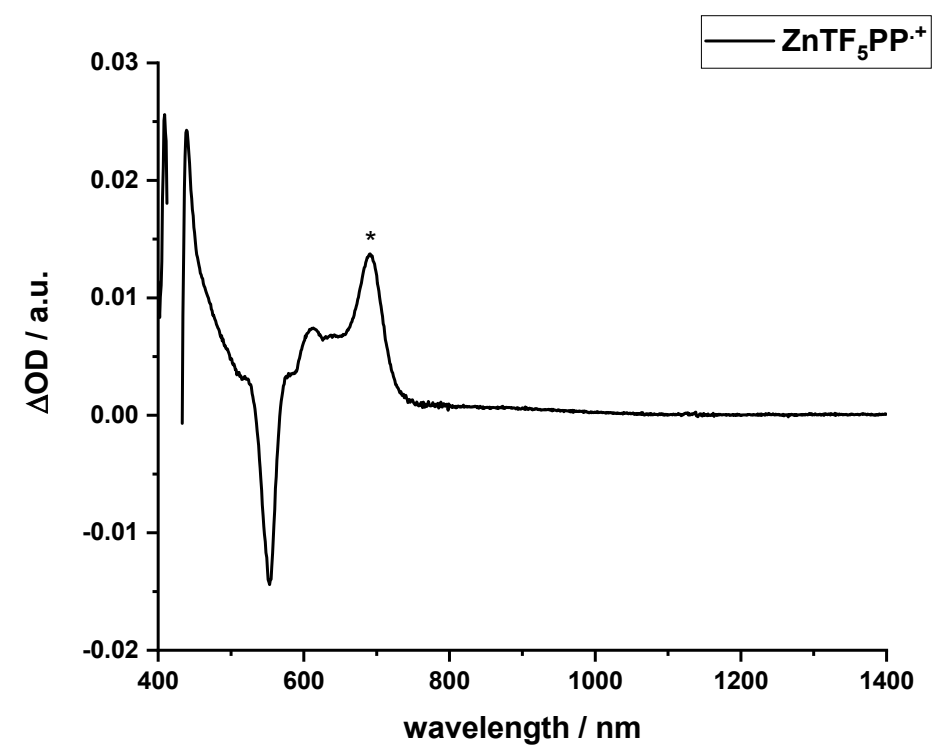

Figure S 8: spectroelectrochemical oxidation of $\mathrm{ZnTF}_{5} \mathrm{PP}$ in o-DCB with $0.2 \mathrm{M}$ of $\mathrm{TBA} \mathrm{ClO}_{4}$. * peak likely enhanced by coordination of $\mathrm{ClO}_{4}^{-}$to $\mathrm{ZnTF}_{5} \mathrm{PP}+{ }^{+}$ 

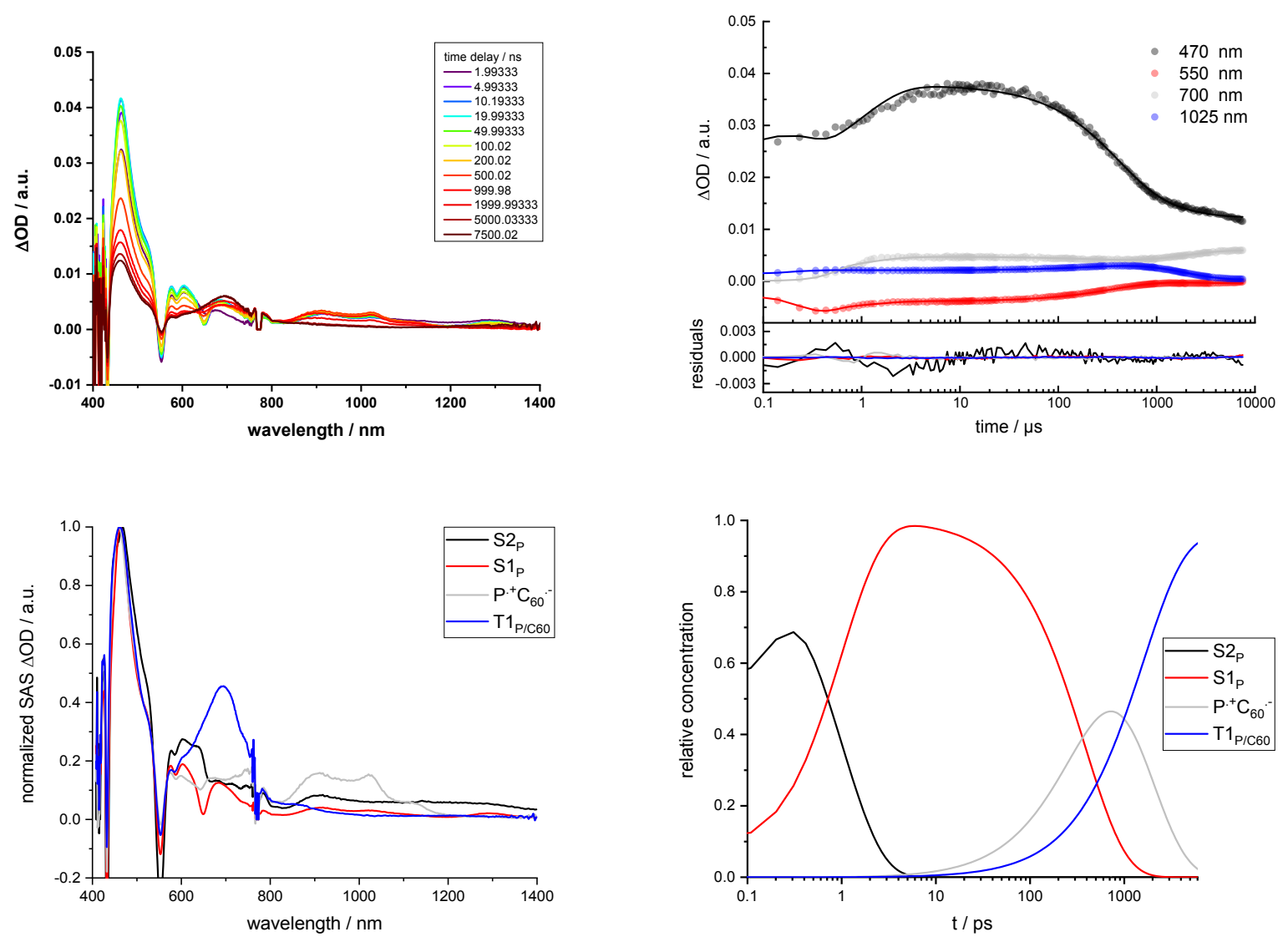

Figure S 9: Transient absorption results of $\mathrm{ZnTF}_{5} \mathrm{PP}_{-} \mathrm{C}_{60}$ on the sub-ps to ns time scale in Toluene upon excitation at 430 $\mathrm{nm}$. Top left: raw data (vis and NIR) with time delays from 2 to 5000 ps after excitation; detector change and probe fundamental at $775 \mathrm{~nm}$. Top right: time profiles of important features and the corresponding fits / residuals obtained from global target analysis. Bottom left: Species associated spectra (SAS) obtained from global target analysis (vis and NIR). Bottom right: time-concentration profiles of the species obtained from global target analysis. Note: $\mathrm{T}_{\mathrm{P}}$ and $\mathrm{T} \mathrm{1}_{\mathrm{C} 6 \mathrm{o}}$ cannot be deconvoluted on this time scale since their decay times are orders of magnitude outside the measurement time window. 

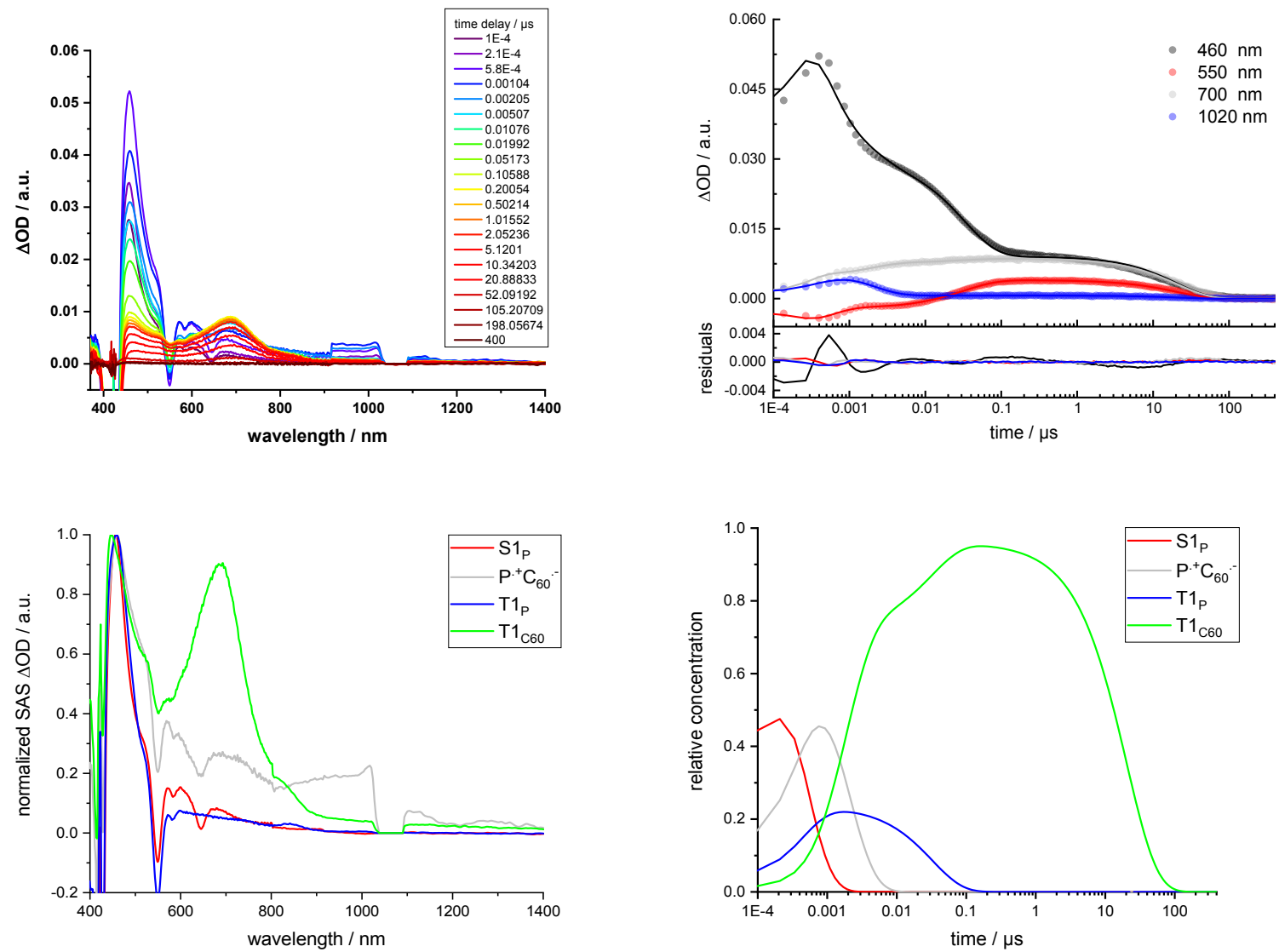

Figure S 10: Transient absorption results of $\mathrm{ZnTF}_{5} \mathrm{PP}_{-} \mathrm{C}_{60}$ on the ns to $\mu$ s time scale in Toluene upon excitation at $430 \mathrm{~nm}$. Top left: raw data (vis and NIR) with time delays from 0.0001 to $400 \mu$ s after excitation; detector change at $914 \mathrm{~nm}$, probe fundamental at $1064 \mathrm{~nm}$. Top right: time profiles of important features and the corresponding fits / residuals obtained from global target analysis. Bottom left: Species associated spectra (SAS) obtained from global target analysis (vis and NIR). Bottom right: time-concentration profiles of the species obtained from global target analysis. Note: S2p cannot be resolved here due to the time resolution of $\sim 1 \mathrm{~ns}$; deconvolution of $\mathrm{S}_{1_{\mathrm{P}}}$ and $\mathrm{P}^{++}-\mathrm{C}_{60}{ }^{-}$-is partially hampered by limited separability for species with lifetimes close to the time resolution limit. 


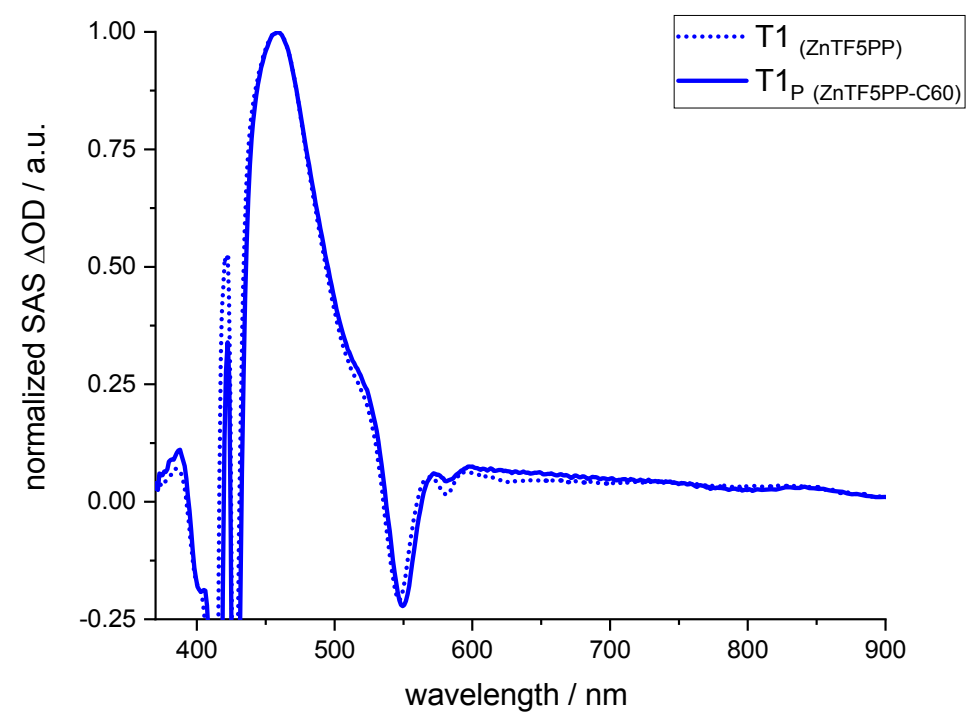

Figure S 11: Comparison of species associated spectra for the $\mathbf{Z n} \mathbf{T F}_{5} \mathbf{P P}$ triplet excited state (as depicted in Figure S9 bottom left) and the porphyrin triplet excited state in $\mathbf{1}$ (as depicted in Figure S13 bottom left), resulting from global target analysis with parameters as given in Figure Sil and Figure 5. 


\section{Experimental section}

NMR. ${ }^{1} \mathrm{H}$ NMR spectra were taken at $600 \mathrm{MHz}$ on a Bruker Avance NEO spectrometer equipped with a DCH cryo probe. Chemical shifts were referenced by residual $\mathrm{CHCl}_{3}(7.24 \mathrm{ppm}) .{ }^{19} \mathrm{~F}$ NMR spectra were taken at $500 \mathrm{MHz}$ on a Bruker Avance NEO spectrometer equipped with a PA TBO probe. Chemical shifts referenced to $\mathrm{C}_{6} \mathrm{~F}_{6}(-164.9 \mathrm{ppm})$.

MS. A concentration of $10^{-5} \mathrm{~mol} \mathrm{~L}^{-1}$ of 1 in a mixture of dichloromethane:acetonitrile $(1: 2, \mathrm{~V}: \mathrm{V})$ was used as the sample solution for the electrospray ionization (ESI) experiments. The solvents were of HPLC grade purity and used as provided. Mass spectra were recorded with a micrOTOF Q-II (Bruker, Bremen, Germany) equipped with an electrospray ion source using nitrogen as nebulizing gas and a collision cell also utilizing nitrogen as collision gas. The instrument was operated in the negative-ion mode and the capillary voltage was set to $4 \mathrm{kV}$ to obtain sufficient electrochemical reduction of the analyte. For the fragmentation experiment (MS/MS spectrum) the radical anion of the analyte was mass selected and subsequently accelerated with a potential of $35 \mathrm{~V}$ before entering the collision cell.

Electrochemistry. 1 and $\mathbf{Z n T F}_{5} \mathrm{PP}$ reference were dissolved in ortho-dichlorobenzene (o-DCB) with addition of $0.2 \mathrm{M}$ of electrolyte tetrabutylammonium perchlorate $\left(\mathrm{TBAClO}_{4}\right)$. Potentials were measured against an $\mathrm{Ag} \mid \mathrm{AgNO}_{3}$ reference electrode, while ferrocene was used as external standard. Prior to any measurements, the Solutions $(2-5 \mathrm{ml})$ were flushed with Argon for at least 20 minutes. Both were investigated by Squarewave Voltammetry within a window of approximately $3.5 \mathrm{~V}(-2 \mathrm{~V}$ to $1.5 \mathrm{~V}$ vs $\left.\mathrm{Ag} \mid \mathrm{AgNO}_{3}\right)$ and without showing any signs of solvent electrolysis.

Time-resolved transient absorption spectroscopy. Time resolved transient absorption spectra with $150 \mathrm{fs}$ resolution and time delays from 0 to 7500 ps were acquired using Ultrafast Systems HELIOS Femtosecond Transient Absorption Spectrometer. The laser source was a Clark MXR CPA2110 Ti:Sapphire amplifier with a pulsed output of $775 \mathrm{~nm}$ at $1 \mathrm{kHz}$ and pulse width of $150 \mathrm{fs}$. Visible white light ( 400-770 nm) was generated by focusing a fraction of the fundamental $775 \mathrm{~nm}$ output onto a $2 \mathrm{~mm}$ sapphire disk; for the (near) IR (780-1500 nm), a $1 \mathrm{~cm}$ sapphire was used. Excitation pulses of $430 \mathrm{~nm}$ wavelength were generated by a NOPA with subsequent frequency doubling; a bandpass filter with $\pm 5 \mathrm{~nm}$ was used to ensure low spectral width and to exclude 775 and $387 \mathrm{~nm}$ photons.

Ultrafast Systems EOS Sub-Nanosecond Transient Absorption Spectrometer was employed to measure transient absorption spectra with time delays of $1 \mathrm{~ns}$ to $400 \mu \mathrm{s}$ with $1 \mathrm{~ns}$ time resolution. The laser source for excitation was a Clark MXR CPA2101 Ti:Sapphire amplifier with a pulsed output of $775 \mathrm{~nm}$ at $1050 \mathrm{~Hz}$ and pulse width of $150 \mathrm{fs}$. Excitation pulses of $430 \mathrm{~nm}$ wavelength were generated by a NOPA with subsequent frequency doubling; a bandpass filter with $\pm 5 \mathrm{~nm}$ was used to ensure low spectral width and to exclude 775 and $387 \mathrm{~nm}$ photons. White light ( 370 to $>1600 \mathrm{~nm}$ ) was generated by a built-in photonic crystal fiber supercontinuum laser source with a fundamental of $1064 \mathrm{~nm}$ at $2 \mathrm{kHz}$ output frequency and pulse width of approximately 1 ns.

$\mathrm{ZnTF}_{5} \mathrm{PP}$ and 1 were probed by transient absorption experiments on the sub-ps to ns and ns to $\mu$ s time scales upon excitation into the Soret-band absorption at $430 \mathrm{~nm}$ with pulse lengths of about $200 \mathrm{fs}$. Toluene was used as solvent in all experiments. Solutions were flushed with Ar for 15-20 min prior to measurements. 